\title{
Characterization of diffusivity-based oxygen transport in Arctic organic soil
}

Deepagoda Thuduwe Kankanamge Kelum, Chamindu; Elberling, Bo

Published in:

European Journal of Soil Science

DOI:

10.1111/ejss. 12293

Publication date:

2015

Document version

Publisher's PDF, also known as Version of record

Document license:

CC BY-NC-ND

Citation for published version (APA):

Deepagoda Thuduwe Kankanamge Kelum, C., \& Elberling, B. (2015). Characterization of diffusivity-based oxygen transport in Arctic organic soil. European Journal of Soil Science, 66(6), 983-991.

https://doi.org/10.1111/ejss.12293 


\title{
Characterization of diffusivity-based oxygen transport in Arctic organic soil
}

\author{
T. K. K. C H A M I D U D E E P A G O A \& B. E L B E R L I N G \\ Department of Geosciences and Natural Resource Management, Center for Permafrost (CENPERM), University of Copenhagen, Øster \\ Voldgade 10, DK-1350 Copenhagen, Denmark
}

\begin{abstract}
Summary
Arctic terrestrial ecosystems are characterized by large deposits of near-surface soil organic carbon in poorly drained areas. Recent changes in Arctic regions such as warming and changes in water balance have adverse effects on the dynamics of near-surface oxygen, leading to a potential increase in oxidation of near-surface carbon and emission of $\mathrm{CO}_{2}$. This study investigated oxygen diffusivity characteristics, in both gaseous and liquid phases, in the upper $10 \mathrm{~cm}$ of an organic soil profile from a peatland in Disko, West Greenland $\left(69^{\circ} \mathrm{N}\right)$. Two commonly used methods for calculating diffusivity of gaseous-phase oxygen were applied and discussed to select the most appropriate method for highly porous media, for example peat soil. We measured diffusivity of gaseous-phase oxygen with a one-chamber diffusion set-up in soil at different air contents (mimicking draining), and described it numerically with a previously developed parametric diffusivity model. We obtained precise measurements of liquid-phase oxygen diffusivity along a depth profile $(0-2 \mathrm{~cm})$ in water-saturated peat soil with a diffusivity microsensor coupled to a micromanipulator. The results show that the choice of an appropriate diffusivity model is critical for predicting oxygen diffusivity in organic soil and that diffusivity in mineral soil is not representative for organic soil. Furthermore, the importance of the non-linear functionality between water saturation and diffusivity is demonstrated. This highlights the importance of measuring and modelling oxygen diffusivity rather than relying on measurements of observed water content in future studies of $\mathrm{CO}_{2}$ and $\mathrm{CH}_{4}$ dynamics in Arctic soil systems subject to climate changes
\end{abstract}

\section{Introduction}

Almost $40 \%$ of the global near-surface soil carbon occurs in Arctic soil (McGuire etal., 2009; Tarnocai etal., 2009); it is more or less affected by underlying impermeable permafrost (i.e. below $0^{\circ} \mathrm{C}$ over more than two consecutive years). The permafrost table acts as a barrier to infiltration and thereby controls oxygen availability above. Changes in water balance and thawing of permafrost are expected to influence net greenhouse gas dynamics and budgets; therefore, they represent one of the most critical feedback mechanisms of climate changes in the Arctic (Arctic Monitoring and Assessment Program, AMAP, 2011; Hugelius et al., 2014).

Decomposition of subsurface carbon and subsequent production of $\mathrm{CH}_{4}$ from Arctic soil is greatly inhibited by the characteristic cold environment in spite of large reserves of C (Jonasson et al., 2001). Furthermore, the typically waterlogged conditions in Arctic

Correspondence: B. Elberling. E-mail: be@ign.ku.dk

Received 7 October 2014; revised version accepted 16 June 2015 peatlands have limited oxygen availability, which leads to less oxidation of $\mathrm{CH}_{4}$ and, therefore, limited atmospheric emission of $\mathrm{CO}_{2}$ (Elberling et al., 2011). However, recent climate-induced changes in Arctic regions, including Arctic warming (Post et al., 2009) and draining of peatlands (Holden et al., 2006), have given rise to an increased risk of the thawing of permafrost and enhanced aeration of organic topsoil layers.

Subsurface $\mathrm{O}_{2}$ transport and $\mathrm{CO}_{2}$ emissions across the soil-atmosphere continuum are predominantly diffusion limited (Penman, 1940), particularly in the absence of near-surface wind- or temperature-induced pressure fluctuations. The gas diffusion coefficient in soil water, $D_{\mathrm{s}, \mathrm{l}}\left(\mathrm{cm}^{2} \mathrm{~s}^{-1}\right)$, and that in soil air, $D_{\mathrm{s}, \mathrm{g}}$ $\left(\mathrm{cm}^{2} \mathrm{~s}^{-1}\right)$, are responsible for regulating diffusion-controlled transport of gases through soil liquid and gaseous phases, respectively. The two gas diffusion coefficients are conveniently scaled by their respective gas diffusion coefficients and expressed as gas diffusivity in the liquid phase $\left(D_{\mathrm{s}, \mathrm{l}} / D_{\mathrm{o}, \mathrm{l}}\right)$ and in the gaseous phase $\left(D_{\mathrm{s}, \mathrm{g}} / D_{\mathrm{o}, \mathrm{g}}\right)$, where $D_{\mathrm{o}, \mathrm{l}}$ and $D_{\mathrm{o}, \mathrm{g}}$ are oxygen gas diffusion coefficients in free water and free air, respectively, under standard conditions. This scaling standardizes the gas-specific characteristics of the diffusion 
coefficients, which makes diffusivity a descriptive property controlled by the functional fluid (liquid or gaseous) phase, mainly the water content and pore network continuity. Notably, gas diffusion in water is, in general, four orders of magnitude slower than gas diffusion in air under the same ambient conditions. For example, for oxygen, $D_{\mathrm{o}, \mathrm{l}}=2.10 \times 10^{-5} \mathrm{~cm}^{2} \mathrm{~s}^{-1}\left(20^{\circ} \mathrm{C}\right.$ and zero salinity; Broecker \& Peng, 1974) and $D_{\mathrm{o}, \mathrm{g}}=0.205 \mathrm{~cm}^{2} \mathrm{~s}^{-1}\left(20^{\circ} \mathrm{C}\right.$ and $1.013 \times 10^{5} \mathrm{~Pa}$ pressure; Rolston \& Moldrup, 2012). The relative importance of the two processes depends on which coefficient controls the dominant diffusion mechanism with respect to the existing subsurface conditions (for example, water-logged or drained). Therefore, accurate estimation of both diffusion coefficients is essential for proper characterization of subsurface systems. Different methods have been suggested in the literature for measuring and calculating the diffusion coefficients; however, their applicability and usefulness vary depending on the characteristics of the particular medium. There is a lack of diffusivity data for organic soil that embrace the entire range of water content (0-100\% saturation) because no single method seems to be suitable for assessing the sensitivity of diffusivity over this range of water content. Thus, a combination of methods is important but is seldom used (Elberling \& Damgaard, 2001), in particular for organic-rich soil. The importance of direct measurements of soil-gas diffusivity is also highlighted in modelling climate changes in Arctic regions because most of the recent predictions of greenhouse-gas-induced climate change still rely on the commonly used gas diffusivity models (e.g. Millington \& Quirk, 1961 model), which have not been validated for ecosystem-specific measurements.

This study examines oxygen diffusivity characteristics in topsoil layers $(0-10 \mathrm{~cm})$ sampled from a peat in Disko, West Greenland. We measured diffusivity of liquid-phase oxygen in water-saturated conditions that represent the natural water-logged (wetland) conditions typical of the region. We also measured the diffusivity of gaseous-phase oxygen under varying moisture conditions to represent evapotranspiration or drawdown of the water table in peat soil. This enabled us to test the following hypotheses: (i) standard methods for calculating the diffusion coefficient $\left(D_{\mathrm{s}, \mathrm{g}}\right)$ of gaseous-phase oxygen are not equally suitable for modelling diffusivity for organic soil and (ii) diffusivity measurements under fully water-saturated conditions are critical to constrain fitting of the equations. The sensitivity of diffusion models in the range of near-saturated conditions is seldom evaluated because of experimental difficulties in maintaining steady-state conditions during measurement.

\section{Materials and methods}

\section{Soil}

Intact cores of soil $(35 \mathrm{~cm} \times 25 \mathrm{~cm} \times 30 \mathrm{~cm})$ were sampled from the top horizon of an experimental field on Disko Island, West Greenland $\left(69^{\circ} \mathrm{N}, 53^{\circ} \mathrm{W}\right)$, which is near to the transition zone between the low and high Arctic. The site is on a young marine terrace and the soil is predominantly peat. The snow cover is up to $1 \mathrm{~m}$ and persists
Table 1 Characteristics of the Arctic peat soil from Disko, Greenland

\begin{tabular}{|c|c|c|c|c|c|c|c|}
\hline Location & $\begin{array}{l}\text { Depth / } \\
\mathrm{cm}\end{array}$ & $\begin{array}{l}\text { Soil } \\
\text { type }\end{array}$ & 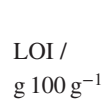 & $\begin{array}{l}\mathrm{C}: \mathrm{N} \\
\text { ratio }\end{array}$ & $\begin{array}{l}\text { Total } \\
\text { porosity / } \\
\mathrm{cm}^{3} \mathrm{~cm}^{-3}\end{array}$ & $\begin{array}{l}\text { Particle } \\
\text { density / } \\
\mathrm{g} \mathrm{cm}^{-3}\end{array}$ & $\begin{array}{l}\text { Dry bulk } \\
\text { density / } \\
\mathrm{g} \mathrm{cm}^{-3}\end{array}$ \\
\hline Disko & $0-5$ & Peat & $95.7 \pm 3$ & $25.9 \pm 4$ & 0.84 & 1.16 & 0.17 \\
\hline Disko & $5-10$ & Peat & $92.1 \pm 3$ & $26.8 \pm 3$ & 0.70 & 1.27 & 0.25 \\
\hline
\end{tabular}

LOI is the loss on ignition and standard deviations $(n=3)$ are shown as \pm .

until mid-June. According to the meteorological measurements of the station (1991-2004; Hansen etal., 2006), the mean air temperatures of the warmest (July) and the coldest (February-March) months are 7.1 and $-16.0^{\circ} \mathrm{C}$, respectively. The mean annual soil temperature at $5-\mathrm{cm}$ depth is $-1.9^{\circ} \mathrm{C}$ and permafrost occurs within the top $1 \mathrm{~m}$. The vegetation cover is characterized by contrasting plant types that include moss, Salix Arctophila, Cockerell, Salix Arctica, Pall, Pyrola Grandiflora, Radius, Carex L., Deschampsia Alpine (L.) Roem. \& Schult. and Sphagnum, L. The measured properties of the soil are given in Table 1.

Intact cores that included the vegetation cover were taken in July 2013. Cores were transferred and stored at $7^{\circ} \mathrm{C}$ in the temperature-controlled laboratory at the Center for Permafrost (CENPERM), the University of Copenhagen, Denmark. Subsequently, the vegetation cover, predominantly moss, was removed and subsamples were taken from 0 to $5-\mathrm{cm}$ and from 5 to $10-\mathrm{cm}$ depths with an annular steel cylinder $(6.06 \mathrm{~cm}$ in diameter, $3.48 \mathrm{~cm}$ in height and $\sim 100 \mathrm{~cm}^{3}$ in volume) with minimal soil disturbance. The $D_{\mathrm{s}, 1}$ was measured in saturated samples only, whereas $D_{\mathrm{s}, \mathrm{g}}$ was measured under different moisture conditions achieved by stepwise evaporation of samples at in situ moisture conditions. After each evaporation step, samples were sealed and sufficient time was allowed for water to redistribute to ensure equilibrium conditions before the next measurement. To avoid bypass air flow in dry samples with visible shrinkage, a thin layer of grease was smeared around the annular edge before measurement.

To examine the effect of soil structure on $D_{\mathrm{s}, 1}$ and $D_{\mathrm{s}, \mathrm{g}}$ coefficients, measurements were also made in homogenized samples after first being passed through a $1-\mathrm{mm}$ sieve and subsequently repacked. Soil samples from both layers $(0-5$ and $5-10 \mathrm{~cm})$ were mixed uniformly before sieving. Sieving eliminated large plant and root residues only, and thin hair-like root sections remained in the repacked samples. All measurements were made in triplicate.

In addition, $D_{\mathrm{s}, \mathrm{g}}$ data from the literature (Chamindu Deepagoda et al., 2011a, 2011b, 2013; Masís-Meléndez et al., 2014) on different types of soil and porous media were considered for comparison of the two methods of calculation used by Taylor (1949) and Currie (1960).

\section{Peat characteristics}

Loss on ignition was used to determine organic carbon (OC) content according to Heiri et al. (2001). After being air-dried, samples were homogenized and burned at $550^{\circ} \mathrm{C}$ for 5 hours to determine the percentage weight loss of organic matter. This weight was 
converted to $\mathrm{OC}$ using a factor of 0.58 , which is the generally accepted carbon fraction of soil organic matter. Total nitrogen was measured by the Kjeldahl method (Bremner \& Mulvaney, 1982) and used to calculate the $\mathrm{C}: \mathrm{N}$ ratio. Measurements were replicated three times $(n=3)$.

\section{Liquid-phase $\mathrm{O}_{2}$ diffusivity}

Oxygen diffusivity in saturated samples was measured with a microscale diffusivity sensor (Unisense, Aarhus, Denmark). The sensor is equipped with an internal gas reservoir from which a trace gas $\left(\mathrm{H}_{2}\right)$ is emitted into the surrounding porous medium. The diffusing gas is detected at the sensor tip by a built-in transducer, which, in response to the build-up in partial pressure, generates a signal (measured in $\mathrm{mA}$ or $\mathrm{mV}$ ) that is read by a picoammeter (2000 PA, Unisense, Aarhus, Denmark). Revsbech et al. (1998) provided a general description of the sensor and the mathematical formulation to describe the sensor signal as a function of the apparent diffusion coefficient of the medium.

To construct a calibration curve, two media with known diffusivities were used: stagnant water and a 40-60 $\mu \mathrm{m}$ unsorted glass bead mixture (Elberling \& Damgaard, 2001). Diffusivity was measured up to $2 \mathrm{~cm}$ from the surface in triplicate at each depth. The microsensor-based method allows rapid and in situ measurement of diffusivity along a depth profile with minimum disturbance (because of small tip size) and strong repeatability, which eliminates difficulties associated with classical methods (e.g. the half-cell method). Furthermore, the microsensor was coupled with an automated micromanipulator to maintain precise control over positioning of the sensor during micro-profiling. However, at present the diffusivity sensor is designed and validated for (and therefore essentially limited to) diffusivity measurements in water-saturated environments.

\section{Diffusivity of gaseous-phase $\mathrm{O}_{2}$}

We used a one-chamber diffusion apparatus to measure the diffusivity of gaseous-phase $\mathrm{O}_{2}$ (Figure 1). The apparatus consists of a chamber made with a $10-\mathrm{mm}$ thick PVC tube. The bottom of the tube was embedded and glued into a $10-\mathrm{mm}$ thick plastic block to ensure an air-tight joint. A 5-mm diameter rubber O-ring was inserted into a groove at the top of the tube, which facilitates positioning of the sample during measurement. Provisions are also made on the chamber wall for flushing with $\mathrm{N}_{2}$ and measuring $\mathrm{O}_{2}$.

The chamber was first flushed with $\mathrm{N}_{2}$ to make it oxygen free. The sample was mounted on top of the chamber and atmospheric $\mathrm{O}_{2}$ was allowed to diffuse freely across the sample into the chamber. The increasing $\mathrm{O}_{2}$ concentration inside the cell was monitored continuously by an optical oxygen sensor (type PSt3, PreSens $\mathrm{GmbH}$, Regensburg, Germany), which transmits the luminescence response (in terms of wave amplitude and phase change) to a multi-channel oxygen meter (OXY-10 mini, PreSens GmbH, Regensburg, Germany). Before measurements were made, the oxygen probe was calibrated for oxygen-free ( $0 \%$ air saturation) and oxygen-saturated (100\% air saturation) conditions.

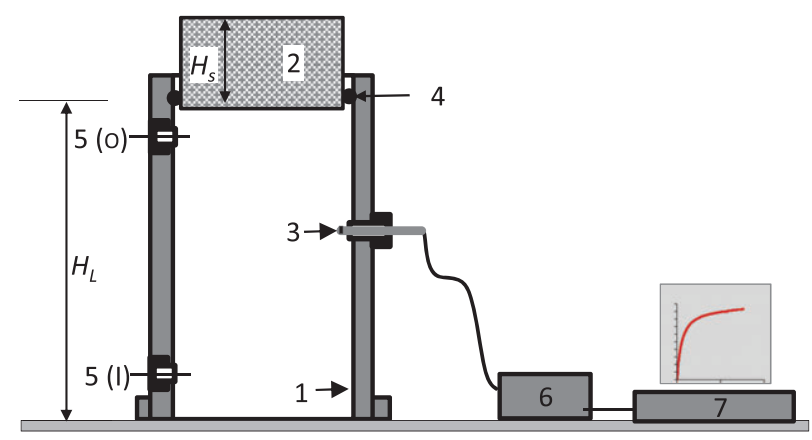

Figure 1 Schematic diagram of the gas diffusion apparatus for measuring diffusivity of gaseous-phase oxygen. 1, diffusion cell; 2, soil sample; 3, optical sensor; 4, O-ring; 5, $\mathrm{N}_{2}$ inlet (I) and outlet (O); 6, oxymeter and datalogger; 7, graphical display.

Prior to the use of actual soil samples, preliminary tests were completed successfully with dummy samples (e.g. solid blocks with and without multi-cylindrical pore systems) to ensure that the chamber was air-tight and gave theoretical $D_{\mathrm{s}, \mathrm{g}}$ values for well-characterized pore systems (see Schjønning etal. (2013) for dummy samples used for pretesting diffusion chambers).

The length of time taken for each measurement varied depending on the moisture status of the sample. For all measurements, the apparatus was kept under a closed hood to avoid undue interference (e.g. from wind, falling objects, and so on). The oxygen meter recorded data for the oxygen profile (oxygen concentration over time), which can be used to calculate $D_{\mathrm{s}, \mathrm{g}}$ with different methods as described below.

\section{Methods for the calculation of $D_{s, g}$}

Two methods have been used commonly for calculating $D_{\mathrm{s}, \mathrm{g}}$ : Taylor (1949) and Currie (1960). Rolston \& Moldrup (2002) provide a detailed account of both methods; therefore, we provide a brief outline only of the mathematical framework behind the two methods to facilitate our subsequent analysis in relation to organic soil.

Taylor's (1949) method. Diffusive fluxes of gases into the soil across a concentration (or partial pressure) gradient follows the classical Fick's first law of diffusion:

$$
J=\frac{Q}{A t}=-D_{\mathrm{s}, \mathrm{g}} \frac{\partial C}{\partial x},
$$

where $J\left[\mathrm{ML}^{2} \mathrm{~T}^{-1}\right]$ is the diffusive gas flux, $Q\left[\mathrm{~L}^{3}\right]$ is the volume of diffusing gas, $C\left[\mathrm{ML}^{-3}\right]$ is the gas concentration, $A\left[\mathrm{~L}^{2}\right]$ is the cross-sectional area of the chamber and $x[\mathrm{~L}]$ and $t[\mathrm{~T}]$ are spatial and temporal dimensions, respectively. Equation (1) can be rewritten in a form that is of interest to our study as follows:

$$
\frac{\mathrm{d} Q}{\mathrm{~d} t}=-D_{\mathrm{s}, \mathrm{g}} A \frac{\Delta C_{t}}{H_{\mathrm{s}}},
$$


where $\Delta C_{t}$ is the change in concentration inside the chamber $\left(C_{t=t}-C_{t=0}\right)$ and $H_{\mathrm{s}}[\mathrm{L}]$ is the sample height.

Alternatively, the volume of gas diffusing into the chamber can be expressed as:

$$
\frac{\mathrm{d} Q}{\mathrm{~d} t}=H_{\mathrm{c}} A \frac{\mathrm{d}\left(\Delta C_{t}\right)}{\mathrm{d} t},
$$

where $H_{\mathrm{c}}[\mathrm{L}]$ is the height of the chamber. Combining Equations (2) and (3) and integrating them over time gives:

$$
\begin{gathered}
D_{\mathrm{s}, \mathrm{g}} \mathrm{d} t=-H_{\mathrm{s}} H_{\mathrm{c}} \frac{\mathrm{d}\left(\Delta C_{t}\right)}{\Delta C_{t}}, \\
D_{\mathrm{s}, \mathrm{g}} \int_{0}^{t} \mathrm{~d} t=-H_{\mathrm{s}} H_{\mathrm{c}} \int_{\Delta C_{o}}^{\Delta C_{t}} \frac{1}{\Delta C_{t}} \mathrm{~d}\left(\Delta C_{t}\right),
\end{gathered}
$$

and

$$
\ln \left(\frac{\Delta C_{t}}{\Delta C_{o}}\right)=-\frac{D_{\mathrm{s}, \mathrm{g}}}{H_{s} H_{c}} t
$$

With Equation (6), $D_{\mathrm{s}, \mathrm{g}}$ can be computed from the gradient of the plotted values $\ln \left(\frac{\Delta C_{t}}{\Delta C_{0}}\right)$ against $t$.

Currie's (1960) method. Linking Fick's first law, Equation (1), with the continuity equation (Rolston \& Moldrup, 2002, Equation [4.3-2]) leads to Fick's second law of diffusion, which can be generally expressed as:

$$
\varepsilon \frac{\partial C}{\partial t}=D_{\mathrm{s}, \mathrm{g}} \frac{\partial^{2} C}{\partial x^{2}}
$$

where $\varepsilon\left[\mathrm{L}^{3} \mathrm{~L}^{-3}\right]$ is the air-filled porosity. An analytical solution to Equation (7) under the boundary conditions specific to the diffusion system is given by Carslaw \& Jaeger (1959) as:

$$
\frac{\Delta C_{t}}{\Delta C_{0}}=\sum_{n=1}^{\infty} \frac{2 h \exp \left(-D_{\mathrm{s}, \mathrm{g}} \alpha_{n}^{2} t / \varepsilon\right)}{H_{\mathrm{s}}\left(\alpha_{n}^{2}+h^{2}\right)+h},
$$

where $h=\varepsilon / H_{\mathrm{c}}$, and $\alpha_{n}$ with $n=1,2,3 \ldots$ are the positive roots of the equation:

$$
\left(\alpha H_{\mathrm{s}}\right) \tan \left(\alpha H_{\mathrm{s}}\right)=h H_{\mathrm{s}} .
$$

If the terms for $n \geq 2$ are disregarded, then:

$$
\frac{\Delta C_{t}}{\Delta C_{0}}=\frac{2 h \exp \left(-D_{\mathrm{s}, \mathrm{g}} \alpha_{1}^{2} t / \varepsilon\right)}{H_{\mathrm{s}}\left(\alpha_{1}^{2}+h^{2}\right)+h} .
$$

Rewriting Equation (10) in a linear form gives:

$$
\ln \left(\frac{\Delta C_{t}}{\Delta C_{0}}\right)=-\frac{D_{\mathrm{s}, \mathrm{g}} \alpha_{1}^{2}}{\varepsilon} t+\ln \left(\frac{2 h}{H_{\mathrm{s}}\left(\alpha_{1}^{2}+h^{2}\right)+h}\right) .
$$

Following Equation (11), $D_{\mathrm{s}, \mathrm{g}}$ can then be calculated from the gradient of the plotted values $\ln \left(\frac{\Delta C_{t}}{\Delta C_{o}}\right)$ against $t$.

Predictive models for $D_{\mathrm{s}, \mathrm{g}} / D_{\mathrm{o}, \mathrm{g}}$

A wide range of soil-gas diffusivity models that express $D_{\mathrm{s}, \mathrm{g}} / D_{\mathrm{o}, \mathrm{g}}$ as a function of properties that can be measured easily, such as air-filled porosity $(\varepsilon)$ and total porosity $(\Phi)$, have been proposed for soil types with different textures and structures in the literature (e.g. Buckingham, 1904; Millington \& Quirk, 1961; Moldrup et al., 2000). For aggregated soil with two-region characteristics, that is inter-aggregate and intra-agregate regions, such as the soil we consider in this study (discussed later), Chamindu Deepagoda et al. (2011b) proposed the generalized density-corrected (GDC) gas diffusivity model, which is given as:

Inter-aggregate region:

$$
\frac{D_{\mathrm{s}, \mathrm{g}}}{D_{\mathrm{o}, \mathrm{g}}}=\alpha\left(\frac{\varepsilon}{\Phi_{i}}\right)^{\beta} \quad 0 \leq \varepsilon \leq \Phi_{i},
$$

where

$$
\alpha=\left.\frac{D_{\mathrm{s}, \mathrm{g}}}{D_{\mathrm{o}, \mathrm{g}}}\right|_{\varepsilon=\Phi_{i}}
$$

and $\beta$ is the shape factor that characterizes non-linearity in the inter-aggregate region, whereas $\Phi_{i}$ denotes the inter-aggregate porosity.

For the intra-aggregate region, Chamindu Deepagoda etal. (2011b) proposed a linear gas $D_{\mathrm{s}, \mathrm{g}} / D_{\mathrm{og}, \mathrm{g}}$ model, which takes the form:

Intra-aggregate region:

$$
\frac{D_{\mathrm{s}, \mathrm{g}}}{D_{\mathrm{o}, \mathrm{g}}}=\alpha+\lambda\left(\varepsilon-\Phi_{i}\right) \quad \Phi_{i} \leq \varepsilon \leq \Phi,
$$

where $\lambda$ is the characteristic parameter that represents the tortuosity of the intra-aggregate region.

The gaseous phase pore tortuosity $(\tau)$ is one of the important porous media characteristics that can be derived from $D_{\mathrm{s}, \mathrm{g}} / D_{\mathrm{o}, \mathrm{g}}$, which can be calculated by (Ball, 1981):

$$
\tau=\sqrt{\frac{\varepsilon}{D_{\mathrm{s}, \mathrm{g}} / D_{\mathrm{o}, \mathrm{g}}}} .
$$

\section{Results and discussion}

A comparison of the Taylor (1949) and Currie (1960) methods

Figure 2 shows a scatterplot that compares the calculated oxygen diffusivity $\left(D_{\mathrm{s}, \mathrm{g}} / D_{\mathrm{o}, \mathrm{g}}\right)$ following Currie (1960) and Taylor (1949) for the Disko soil and different soil types and porous media from the literature (data from Chamindu Deepagoda et al., 2011a, 2011b, 2013; Masís-Meléndez etal., 2014). All measurements have been made with the same type of one-chamber diffusion apparatus using $\mathrm{N}_{2}-\mathrm{O}_{2}$ as the experimental gas pair to ensure that the results are directly comparable. Figure 2 shows a strong agreement $\left(R^{2}=0.99 ; P<0.01, t\right.$-test $)$ between diffusivity values measured by both methods at smaller $D_{\mathrm{s}, \mathrm{g}} / D_{\mathrm{og} g}$ values (which resulted from smaller $\varepsilon$ values). However, there is a tendency for the methods to deviate with larger values of $D_{\mathrm{s}, \mathrm{g}} / D_{\mathrm{o}, \mathrm{g}}>0.25$, especially in very porous media (e.g. particulate porous media). Knowing that $D_{\mathrm{s}, \mathrm{g}} / D_{\mathrm{o}, \mathrm{g}}$ values in typical mineral and weakly-aggregated soil rarely exceed 0.25 (Chamindu Deepagoda et al., 2011a), both 


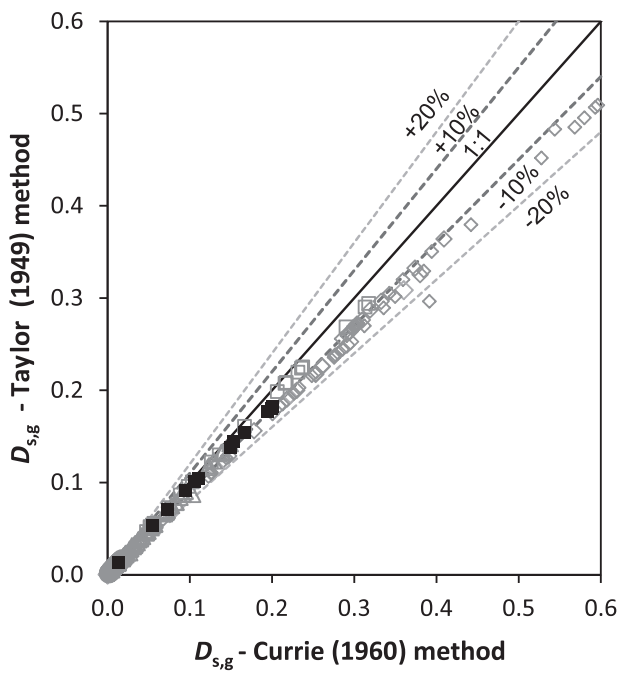

Figure 2 Scatterplot of $D_{\mathrm{s}, \mathrm{g}}$ calculated following Currie's (1960) and Taylor's (1949) methods for selected measurements from the literature. The dashed and dotted lines illustrate $\pm 10 \%$ and $\pm 20 \%$ deviation, respectively, from the 1:1 line. Data from Chamindu Deepagoda etal. (2011a, 2011b, 2013) and Masís-Meléndez et al. (2014). $\diamond$ Particulate porous media (Chamindu Deepagoda et al., 2013); o sandy soil (Jyndevad, Denmark) Masís-Meléndez et al. (2014); $\Delta$ sandy soil (Hjørring, Denmark; Chamindu Deepagoda et al., 2011a); $\square$ andisol aggregates (Nishi-Tokyo; Chamindu Deepagoda et al., 2011b); peat soil (Disko, Greenland; this study).

methods appear to be equally applicable for estimating $D_{\mathrm{s}, \mathrm{g}}$ in general.

For values of $D_{\mathrm{s}, \mathrm{g}} / D_{\mathrm{o}, \mathrm{g}}$ of $0.25-0.6$, the deviation between the estimates from the two methods becomes more pronounced (Figure 2). Taylor's (1949) method underestimated $D_{\mathrm{s}, \mathrm{g}} / D_{\mathrm{o}, \mathrm{g}}$ compared with Currie's (1960) method by about 10-15\% (shown by dashed and dotted lines) for $D_{\mathrm{s}, \mathrm{g}} / D_{\mathrm{o}, \mathrm{g}}>0.4$. This is particularly noticeable in well-structured aggregated soil and particulate porous media or substrates, and under dry conditions. In addition, Taylor's method markedly under-predicts $D_{\mathrm{s}, \mathrm{g}} / D_{\mathrm{og}}$ compared with Currie's method as total porosity increases. The ratio of diffusion coefficients resulting from the two methods, $k\left(D_{\mathrm{s}, \mathrm{g}},{ }_{[\text {Currie] }} / D_{\mathrm{s}, \mathrm{g}},{ }_{[\text {Taylor] }}\right)$, is shown as a function of air-filled porosity in Figure 3 for the same soil types as in Figure 2, but as three groups based on the total porosity. The Disko soil samples are shown separately to differentiate them. The Taylor method under-predicts $D_{\mathrm{s}, \mathrm{g}} / D_{\mathrm{o}, \mathrm{g}}$ by $10-15 \%$ compared with Currie's method for strongly porous soil. This is most evident for relatively dry soil, but there is also a marked deviation under wet conditions (e.g. $\varepsilon=0.2)$. For the Disko soil samples $(0-5 \mathrm{~cm}$; $\Phi=0.83 \mathrm{~cm}^{3} \mathrm{~cm}^{-3}$ ) the maximum deviation is $10 \%$ for the driest condition.

From the above discussion, it is important to assess which of the two methods gives the more accurate estimate. Rolston \& Moldrup (2002) presented Currie's (1960) method as giving the 'true' estimate of $D_{\mathrm{s}, \mathrm{g}}$ and suggested that Taylor's (1949) method under-predicted $D_{\mathrm{s}, \mathrm{g}}$ because it disregards gas storage. Note that Taylor's (1949) method, founded on Fick's first law, does not take into account gas storage in soil as the concentration

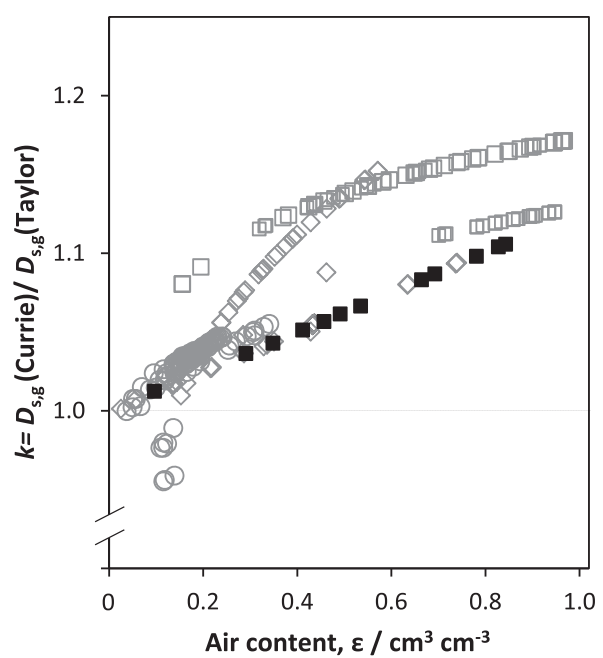

Figure 3 The ratio between the measurements from o and Taylor's (1949) methods, $k\left(D_{\mathrm{s}, \mathrm{g}},[\right.$ Currie] $] D_{\mathrm{s}, \mathrm{g}},[$ Taylor] $)$, as a function of air-filled porosity $(\varepsilon)$ for the same soil types as in Figure 2, but grouped by their total porosity. $\bigcirc \Phi=0.40-0.50 \mathrm{~cm}^{3} \mathrm{~cm}^{-3}$ (Hjorring sand and Jyndevad sand); $\diamond \Phi=0.50-0.80 \mathrm{~cm}^{3} \mathrm{~cm}^{-3}$ (Perlite, Profile, Turface, and aggregared Andisol); $\square \Phi=0.80-1.0 \mathrm{~cm}^{3} \mathrm{~cm}^{-3}$ (pumice, coconut-coir, foamed glass and rockwool); $\Phi=0.83 \mathrm{~cm}^{3} \mathrm{~cm}^{-3}$ (peat soil).

changes, whereas Currie's (1960) method also considers mass conservation through the continuity equation. It is clear, therefore, why under-prediction is so pronounced in strongly porous media (large $\Phi)$, particularly under dry conditions (large $\varepsilon$ ), because large values of $\varepsilon$ together with large $\Phi$ denote marked differences in gas storage. By comparing Equations (6) and (11), Rolston (1986) reported a non-linear increase in $k$, which he presented as a correction factor, with increasing soil air content (normalized by the chamber volume). In addition to the expected increase with air content, our data show a marked increase in $k$ with total porosity even at the same air content. This suggests that reduced accessibility of air-filled pores in strongly porous soil in the presence of water (because of water-induced tortuosity effects) also plays a role in the deviation of $k$ values.

Taylor's (1949) method, however, has a few practical advantages over Currie's (1960) method. Computationally, Taylor's (1949) method is less expensive and requires no iterative procedures (see Equation (9)) or reference tables to calculate $D_{\mathrm{s}, \mathrm{g}}$. Unlike Currie's (1960) method, air-filled porosity $(\varepsilon)$ is not a prerequisite for Taylor's (1949) method and estimates of $\varepsilon$ based on oven-dry weight are feasible as the experiment progresses rather than waiting until the end. This is particularly useful in long experiments with several steps of evaporation- (or suction) controlled moisture adjustment followed by measurement of $D_{\mathrm{s}, \mathrm{g}}$ at each step because $D_{\mathrm{s}, \mathrm{g}}$ can still be estimated at each step even in the event of sample loss or damage before the last step. Overall, the Taylor method is more convenient and gives accurate estimates of $D_{\mathrm{s}, \mathrm{g}}$ for mineral soil $\left(\Phi \approx 0.45 \mathrm{~cm}^{3} \mathrm{~cm}^{-3}\right.$ ); however, a correction is required for soil or porous media with a large porosity, such as organic soil as in this 

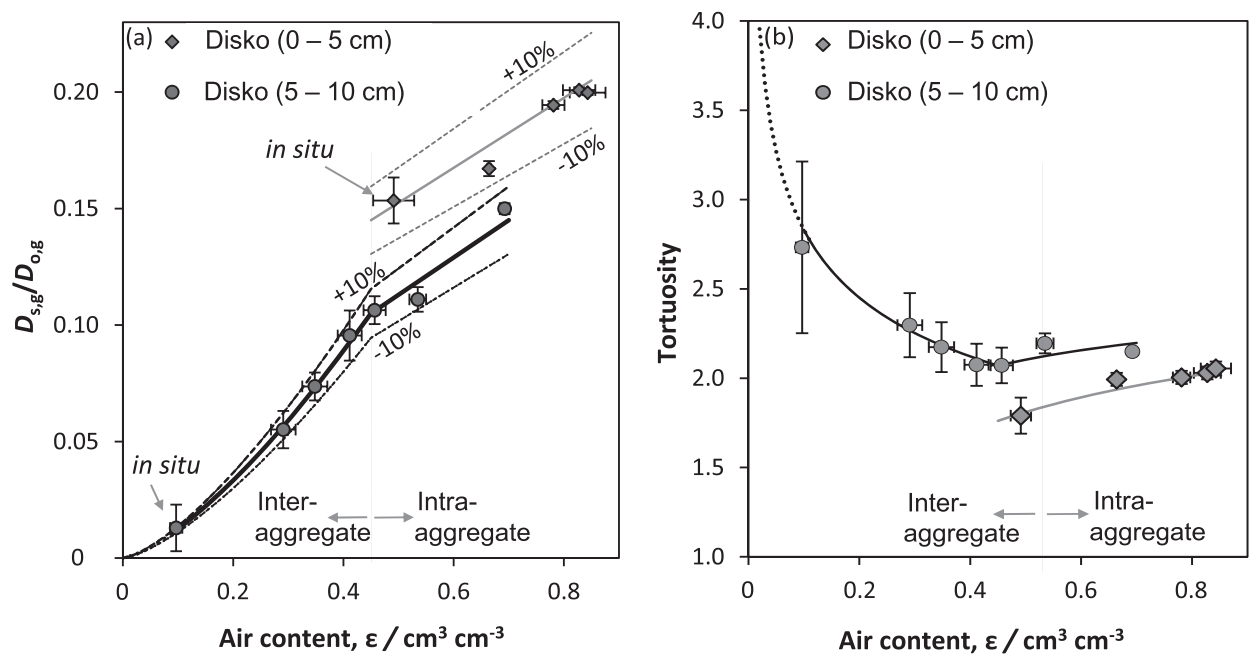

Figure 4 (a) Soil-gas diffusivity, $D_{\mathrm{s}, \mathrm{g}} / D_{\mathrm{o}, \mathrm{g}}$, as a function of air-filled porosity $(\varepsilon)$ for two intact soil samples from the top $(0-5 \mathrm{~cm})$ and lower $(5-10 \mathrm{~cm})$ layers in Disko, Greenland. The solid lines follow the descriptive GDC model, Equations (12) and (13), which fitted best to the top (grey) and lower (black) soil data. Dashed lines in corresponding colours show $\pm 10 \%$ prediction uncertainty from the fitted model. Error bars represent 1 SD from the mean. The vertical dotted line demarcates the inter-aggregate region (left) and intra-aggregate region (right). (b) Gas diffusivity-based pore tortuosity, Equation (14), as a function of air-filled porosity $(\varepsilon)$ for the same soil samples as in (a), together with descriptions of GDC model-based tortuosity. The dotted line shows the model's extrapolation to the region $\left(\varepsilon<0.1 \mathrm{~cm}^{3} \mathrm{~cm}^{-3}\right)$ with no measured data.

study. In the following, Currie's (1960) method is used for all $D_{\mathrm{s}, \mathrm{g}}$ calculations.

\section{Variation in $D_{\mathrm{s}, \mathrm{g}} / D_{o, g}$ and pore tortuosity with soil air content}

Figure $4(\mathrm{a}, \mathrm{b})$ shows $D_{\mathrm{s}, \mathrm{g}} / D_{\mathrm{og} g}$ and pore tortuosity $(\tau)$, respectively, as a function of soil air content $(\varepsilon)$ for soil sampled from the top two layers $(0-5$ and $5-10 \mathrm{~cm})$ at Disko. Measurements were initiated at in situ moisture conditions (as indicated by the arrows) and continued for several air-dry steps. The measured $D_{\mathrm{s}, \mathrm{g}} / D_{\mathrm{o}, \mathrm{g}}$ values agree well with those in the literature for peat soil (e.g. Iiyama \& Hasegawa, 2005). Disko soil, however, is noticeably aggregated and characterized by inter-aggregate and intra-aggregate regions (Figure 4a) demarcated by a boundary. At in situ conditions, the top layer $(0-5 \mathrm{~cm})$ had an air content of $\varepsilon=0.50 \mathrm{~cm}^{3} \mathrm{~cm}^{-3}$; therefore, the inter-aggregate region was already drained and air filled. Consequently, measurements could not be made in the inter-aggregate region. The lower layer $(5-10 \mathrm{~cm})$, on the other hand, had a field air content of $\varepsilon=0.10 \mathrm{~cm}^{3} \mathrm{~cm}^{-3}$ and provided a better indication of $D_{s, g} / D_{\mathrm{o}, \mathrm{g}}$ across a wide range of values of $\varepsilon$. Figure 4(b) shows a clear trend of decreasing pore tortuosity in the inter-aggregate region as evaporation progressed (increasing air content), followed by an increase in tortuosity in the intra-aggregation region as diffusing gas molecules entered more tortuous parts of the pore network within the aggregates.

Figure 4 shows further the predictions from the parameterized GDC model (solid lines), Equations (12) and (13), for the soil from the top (black) and lower (grey) layers. The large value of $\alpha$ observed for the topsoil ( $\alpha=0.15)$ compared with the lower soil layer $(\alpha=0.10)$ can be attributed to the larger amount of partially decayed plant and root residues in the topsoil, which provides an extra pore channelling effect for gas diffusion. Consequently, we would expect a slightly larger $\beta$ for the top layer (could not be determined) than for the lower layer ( $\beta=1.42$, best fit) because $\alpha$ and $\beta$ are considered to be inter-related (Chamindu Deepagoda etal., 2011b). The smaller $\beta$ values we observed for our soil samples compared with those in the literature (varying between 2.5 and 3) suggest favourable characteristics for topsoil aeration. We noticed further that $\lambda$ has almost the same best-fitting values of $0.15-0.16$ for both top and lower samples, which suggests that aggregate matrix tortuosity $(\sqrt{1 / \lambda})$ was less affected by the larger amount of plant residues in the topsoil. The dotted line (Figure 4a,b) shows extrapolations from the GDC model into the wet region $\left(\varepsilon<0.10 \mathrm{~cm}^{3} \mathrm{~cm}^{-3}\right)$ where no measured data were available for detailed analyses.

Figure 4(a) also shows a range of prediction uncertainty of $\pm 10 \%$, denoted by dashed lines in corresponding colours, based on the GDC model. The $10 \%$ prediction uncertainty is broadly within the measurement uncertainty (denoted by error bars) for $\varepsilon<0.45 \mathrm{~cm}^{3} \mathrm{~cm}^{-3}$, where both the Currie and Taylor methods are expected to give comparable estimates. However, for $\varepsilon>0.55 \mathrm{~cm}^{3} \mathrm{~cm}^{-3}$ the $10 \%$ prediction uncertainty clearly exceeds the measurement uncertainty, which suggests marked differences between the two methods.

Figure $5(\mathrm{a}, \mathrm{b})$ shows the variation in $D_{\mathrm{s}, \mathrm{g}} / D_{\mathrm{o}, \mathrm{g}}$ and $\tau$ as a function of air-filled porosity $(\varepsilon)$ in the sieved, repacked samples. The two-region behaviour described above was not evident in the repacked soil samples (Figure 5a) compared with the intact soil (Figure 4a). Tortuosity values declined continuously with increasing $\varepsilon$ in repacked soil (Figure 5b), with no further increase as seen for intact soil (Figure 4b). Although modelling results in small differences in the fitting values for both $\alpha(0.11)$ and $\beta(2.0)$ 

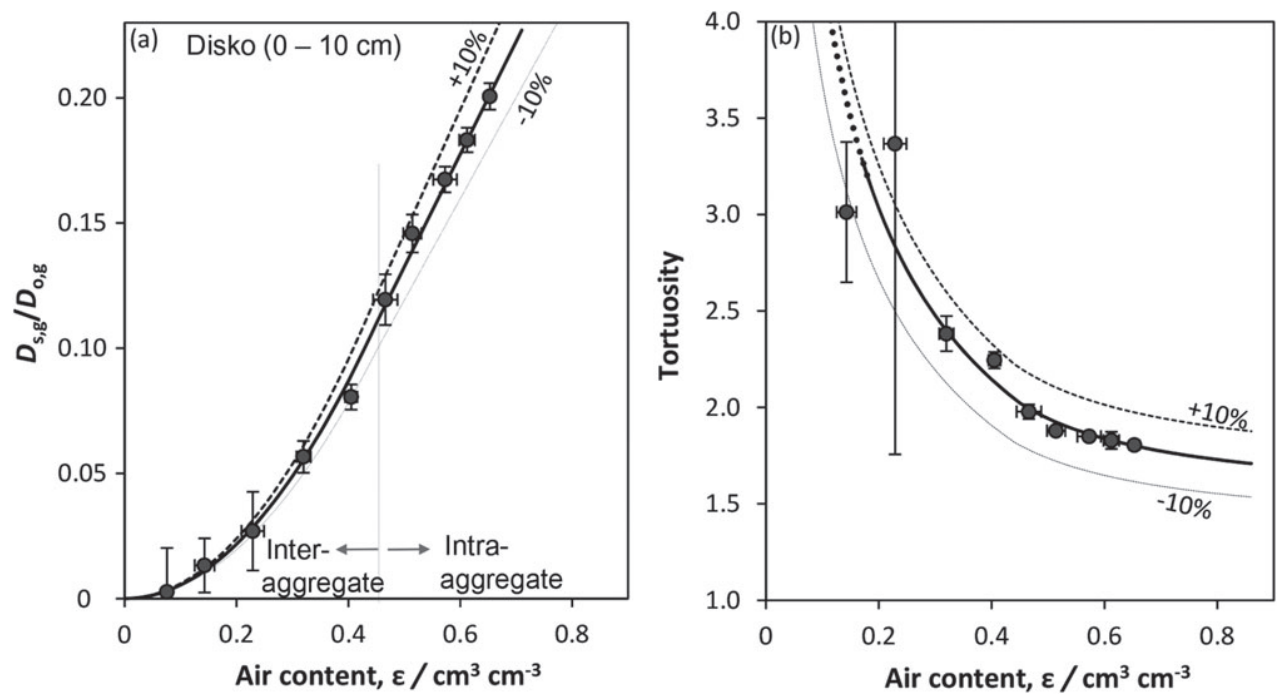

Figure 5 (a) Soil-gas diffusivity, $D_{\mathrm{s}, \mathrm{g}} / D_{\mathrm{o}, \mathrm{g}}$, and (b) $D_{\mathrm{s}, \mathrm{g}} / D_{\mathrm{og}}$-based pore tortuosity, $\tau$, Equation (12), as a function of air-filled porosity ( $\varepsilon$ ) for sieved, repacked soil samples (0-10 cm) from Disko, Greenland. Descriptions of the parametric GDC model, Equations (13) and (14), are also given. Dashed lines show $\pm 10 \%$ prediction uncertainty from the fitted GDC model. Error bars represent 1 SD from the mean. The vertical dotted line demarcates the inter-aggregate region (left) and intra-aggregate region (right).
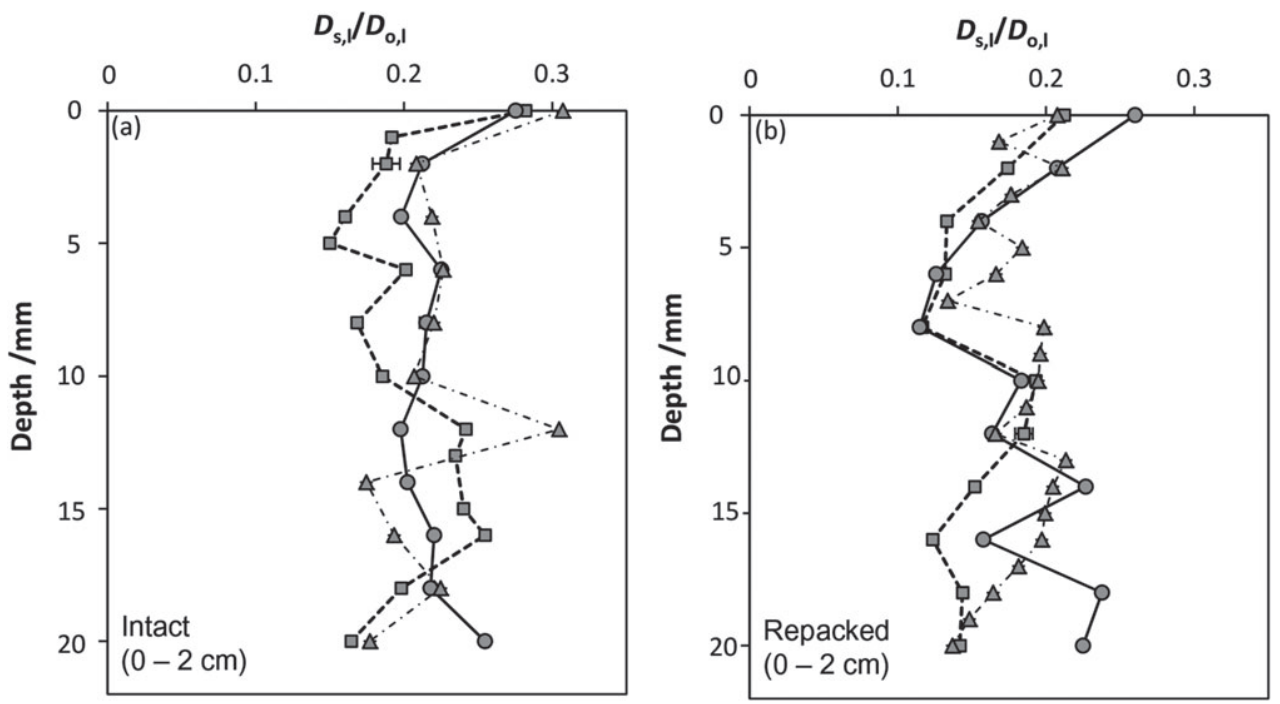

Figure 6 Depth-wise variation of diffusivity in liquid-phase oxygen, $D_{\mathrm{s}, 1} / D_{\mathrm{o}, \mathrm{l}}$, for water-saturated (a) intact and (b) repacked soil samples from Disko, Greenland. In both samples, the measurements were taken at three locations (denoted by different symbols). Error bars represent 1 SD from the mean.

for $\varepsilon \leq 0.45 \mathrm{~cm}^{3} \mathrm{~cm}^{-3}$, there is a sharp and steady increase for $\varepsilon>0.45 \mathrm{~cm}^{3} \mathrm{~cm}^{-3}$ and with $\lambda=0.45$. This is presumably because of the draining of regions associated with uniformly mixed fine root sections that remained after sieving.

\section{Oxygen diffusivity under water-saturated conditions}

Under water-saturated conditions, the air-filled pore space is small $(\varepsilon \approx 0)$ and or remains as isolated air pockets with very little connectivity $(\beta \gg 3)$; both lead to very low diffusivity of gaseous-phase oxygen $\left(D_{\mathrm{s}, \mathrm{g}} / D_{\mathrm{o}, \mathrm{g}} \approx 0\right.$; Equation (13)). The oxygen emission (or uptake) in such cases predominates at the soil-water and atmosphere interface, and the liquid-phase oxygen diffusivity, $D_{\mathrm{s}, \mathrm{l}} / D_{\mathrm{l}, \mathrm{o}}$, becomes the controlling feature for oxygen transport. Figure 6 shows the variation of $D_{\mathrm{s}, \mathrm{l}} / D_{\mathrm{l}, \mathrm{o}}$ measured with a diffusivity microsensor along a depth profile of $0-2 \mathrm{~cm}$.

The results of the microprofile (Figure 6) are shown both for water-saturated intact (a) and repacked (b) samples at three arbitrarily selected locations (shown by different symbols). The error bars are hardly evident at most locations because the diffusivity sensor has good repeatability. On average, the diffusivity of intact samples $\left(D_{\mathrm{s}, \mathrm{l}} / D_{\mathrm{l}, \mathrm{o}}=0.210 \pm 0.03\right)$ is larger than 


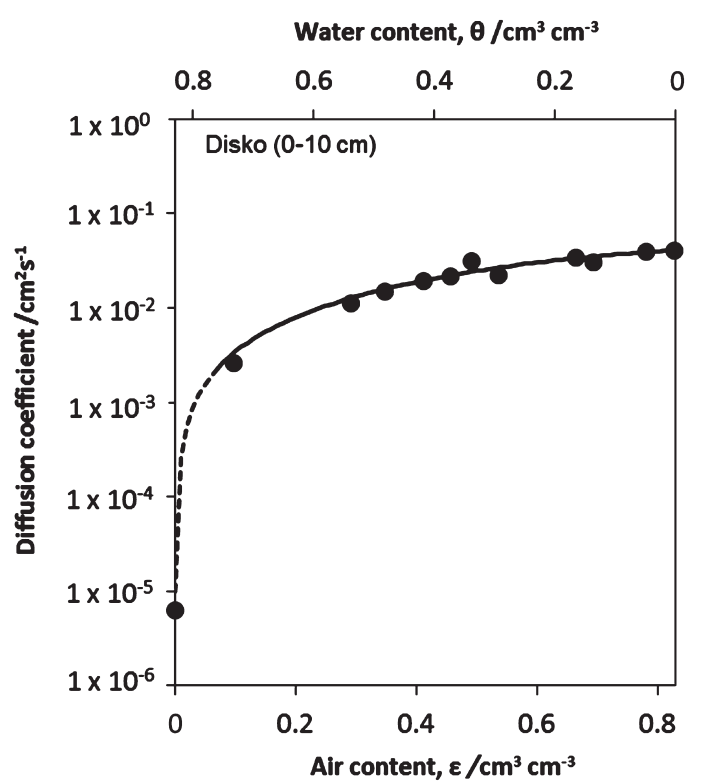

Figure 7 Variation of oxygen diffusion coefficient (Equation (1)) in soil gaseous $\left(\varepsilon>0 \mathrm{~cm}^{3} \mathrm{~cm}^{-3}\right)$ and liquid $\left(\varepsilon=0 \mathrm{~cm}^{3} \mathrm{~cm}^{-3}\right)$ phases as a function of air content $(\varepsilon)$ (lower $x$-axis) and water content $(\theta)$ (top $x$-axis) for topsoil $(0-10 \mathrm{~cm})$ from Disko, Greenland. The solid line shows the observed trend within the partially-saturated region $\left(\varepsilon>0.1 \mathrm{~cm}^{3} \mathrm{~cm}^{-3}\right)$, whereas the dotted line denotes the extrapolation of the fitted model to the region $\left(0<\varepsilon<0.1 \mathrm{~cm}^{3} \mathrm{~cm}^{-3}\right)$ with no measured data.

that for repacked samples $\left(D_{\mathrm{s}, \mathrm{l}} / D_{\mathrm{l}, \mathrm{o}}=0.173 \pm 0.017\right)$, but there is no marked trend with depth for either type of sample. The diffusivity sensor recorded an unrealistically large diffusivity value $\left(D_{\mathrm{s}, \mathrm{I}} / D_{\mathrm{l}, \mathrm{o}}=2.32 \pm 0.001\right)$ for one intact sample at 12-cm depth (not shown in Figure 6) where the sensor tip presumably pierced a partially-saturated isolated air pocket. This is a particular advantage of the microsensor-based approach for diffusivity measurements because it gives a useful qualitative insight into pore-scale heterogeneity and pore characterization. However, the sensor was not designed and calibrated to quantify apparent diffusivity in such variably saturated soil or sediment systems.

The results for oxygen diffusivity of both gaseous and liquid phases of the topsoil $(0-10 \mathrm{~cm})$ indicate that for water-saturated soil, the apparent diffusion coefficient increased by a factor of $4.8 \times 10^{3}$ when the topsoil was $50 \%$ aerated and by a factor of $5.3 \times 10^{3}$ when the soil was $66 \%$ aerated (Figure 7) (without taking account of oxygen diffusivity of the liquid phase in partially-saturated conditions). The diffusivity measurements in saturated soil are important for constraining the fit of the model (Figure 7) as there are no diffusivity data at near-saturated conditions because such data are difficult to obtain. Lack of gaseous phase diffusivity data in near-saturated conditions also hindered a detailed statistical analysis of measurement uncertainties. Gas diffusion in the transition region (gaseous-to-liquid phase) is characterized by a gradual shift from parallel diffusion to serial diffusion; therefore, a method that involves rapid and accurate measurement in both phases is essential to determine the intrinsic uncertainty in this region. We believe that an integrated diffusivity microsensor network that can obtain diffusivity measurements quickly in both fully and partially saturated soils will be the most appropriate method for this purpose.

The results highlight the potentially marked changes in near-surface oxygen transport characteristics when the topsoil is aerated because of climate warming-induced evaporation and or fluctuations in the water level. The increased $\mathrm{CH}_{4}$ dynamics (production or oxidation) and $\mathrm{CO}_{2}$ emissions because of topsoil aeration might, in turn, result in further climate warming. In addition, enhanced topsoil aeration can have adverse consequences for soil chemistry (e.g. increased nutrient mineralization and release) and microbiology (e.g. enhanced microbial metabolism). The observed non-linearity in oxygen diffusivity at varying degrees of saturation emphasized further the importance of direct diffusivity measurements or the use of appropriate diffusivity models in future estimates of oxygen transport, and the need to quantify subsurface $\mathrm{CO}_{2}$ and $\mathrm{CH}_{4}$ dynamics. Close and continuous monitoring of near-surface changes, for example in soil moisture and temperature, is required for improved understanding and better characterization of oxygen dynamics in Arctic terrestrial systems.

\section{Conclusions}

We compared two commonly used methods for calculating gaseous-phase oxygen diffusivity and showed that Currie's (1960) method is more appropriate for peat soil than is Taylor's (1949) method because estimates of the latter were underestimated by almost $10 \%$ under dry conditions. Based on a two-region parametric gas diffusivity model, we described successfully gas phase diffusivity for a range of moisture conditions in peat soil that were not well represented by typical models developed for mineral soil. This highlights the need for measurements of diffusivity in peat soil and the results here show an increase in the apparent oxygen diffusion coefficient by a factor of $4.8 \times 10^{3}$ when the topsoil was $50 \%$ aerated and of $5.3 \times 10^{3}$ when the soil was $66 \%$ aerated. This suggested pronounced changes in the characteristics of oxygen transport in response to changes in near-surface water saturation. The observed non-linearity of oxygen diffusivity highlights the importance of direct diffusivity measurements or the use of an appropriate diffusivity model for future estimates of $\mathrm{CH}_{4}$ and $\mathrm{CO}_{2}$ dynamics. In particular, well-calibrated gas diffusivity models need to be considered in future climate change modelling to assess ecosystem-controlled feedbacks on global warming.

\section{Acknowledgements}

We gratefully acknowledge the financial support for this research from the Danish National Research Council (CENPERM DNRF100). We are also thankful to Lars H. Larsen and Michael Nielsen for technical assistance with diffusivity microsensor measurements and for hosting the Microsensor Workshop (June 2014) in Unisense A/S, Aarhus, Denmark. Finally, we would like to thank the two anonymous reviewers and the editor for their helpful comments. 


\section{References}

AMAP 2011. Snow, Water, Ice and Permafrost in the Arctic (SWIPA): Climate Change and the Cryosphere. Arctic Monitoring and Assessment Programme (AMAP), Oslo.

Ball, B.C. 1981. Modelling of soil pores as tubes using gas permeabilities, gas diffusivities, and water release. Journal of Soil Science, 32, 465-481.

Bremner, J.M. \& Mulvaney, C.S. 1982. Nitrogen-total. In: Methods of Soil Analysis. Part 2. Chemical and Microbiological Properties (ed A.L. Page), pp. 595-624. American Society of Agronomy, Madison, WI.

Broecker, J. \& Peng, T.H. 1974. Gas exchange rates between air and sea. Tellus, 26, 21-35.

Buckingham, E. 1904. Contributions to Our Knowledge of the Aeration of Soils. Bureau of Soils Bulletin 25. U.S. Government Printing Office, Washington.

Carslaw, H.S. \& Jaeger, J.C. 1959. Conduction of Heat in Solids, 2nd edn. Clarendon Press, Oxford.

Chamindu Deepagoda, T.K.K., Moldrup, P., Schjønning, P., de Jonge, L.W., Kawamoto, K. \& Komatsu, T. 2011a. Density-corrected models for gas diffusivity and air permeability in unsaturated soil. Vadose Zone Journal, 10, 226-238.

Chamindu Deepagoda, T.K.K., Moldrup, P., Schjønning, P., Kawamoto, K., Komatsu, T. \& de Jonge, L.W. 2011b. Generalized density corrected model for gas diffusivity in variably saturated soils. Soil Science Society of America Journal, 74, 1302-1317.

Chamindu Deepagoda, T.K.K., Moldrup, P., Tuller, M., Pedersen, M., Chen-Lopez, J.C., de Jonge, L.W. et al. 2013. Gas diffusivity-based design and characterization of greenhouse growth substrates. Vadose Zone Journal, 12, 1-13.

Currie, J.A. 1960. Gaseous diffusion in porous media: part 1. A non steady state method. British Journal of Applied Physiology, 11, 314-317.

Elberling, B. \& Damgaard, L.R. 2001. Microscale measurements of oxygen diffusion and consumption in subaqueous sulphide tailings. Geochimica et Cosmochimica Acta, 65, 1897-1905.

Elberling, B., Askaer, L., Jorgensen, C.J., Joensen, H.P., Kuhl, M., Glud, R.N. et al. 2011. Linking soil $\mathrm{O}_{2}, \mathrm{CO}_{2}$, and $\mathrm{CH}_{4}$ concentrations in a wetland soil: implications for $\mathrm{CO}_{2}$ and $\mathrm{CH}_{4}$ fluxes. Environmental Science \& Technology, 45, 3393-3399.

Hansen, B.U., Elberling, B., Humlum, O. \& Nielsen, N. 2006. Meteorological trends (1991-2004) at Arctic Station, Central West Greenland $\left(69^{\circ} 15^{\prime} \mathrm{N}\right)$ in a 130 years perspective. Danish Journal of Geography, 106, $45-55$.

Heiri, O., Lotter, A.F. \& Lemcke, G. 2001. Loss on ignition as a method for estimating organic carbon and carbonate content in sediments: reproduction and comparability of results. Journal of Paleolimnology, 25, 101-110.

Holden, J., Burt, T.P., Evans, M.G. \& Horton, M. 2006. Impact of land drainage on peatland hydrology. Journal of Environmental Quality, 35, $1764-1778$.

Hugelius, G., Strauss, J., Zubrzycki, S., Harden, J.W., Schuur, E.A.G., Ping, C. et al. 2014. Improved estimates show large circumpolar stocks of permafrost carbon while quantifying substantial uncertainty ranges and identifying remaining data gaps. Biogeosciences Discussion, 11, 4771-4822.

Iiyama, I. \& Hasegawa, S. 2005. Gas diffusion coefficient of undisturbed peat soils. Soil Science and Plant Nutrition, 51, 431-435.

Jonasson, S.E., Shaver, G.R. \& Chapin, F.H. III 2001. Biogeochemistry in the Arctic: patterns, processes and controls. In: Global Biogeochemical Cycles in the Climate System (eds E.D. Schulze, M. Heimann, S.P. Harrison, E.A. Holland, J.J. Lloyd, I.C. Prentice \& D. Schimel), pp. 139-150. Academic Press, Elsevier, London.

McGuire, A.D., Anderson, L.G., Christensen, T.R., Dallimore, S., Guo, L., Hayes, D.J. et al. 2009. Sensitivity of the carbon cycle in the Arctic to climate change. Ecological Monographs, 79, 523-555.

Masís-Meléndez, F., Moldrup, P., Chamindu Deepagoda, T.K.K., Tuller, M. \& de Jonge, L.W. 2014. Gas diffusion-derived tortuosity governs saturated hydraulic conductivity of sandy soils. Journal of Hydrology, 512, 388-396.

Millington, R.J. \& Quirk, J.M. 1961. Permeability of porous solids. Transactions of the Faraday Society, 57, 1200-1207.

Moldrup, P., Olesen, T., Gamst, J., Schjønning, P., Yamaguchi, T. \& Rolston, D.E. 2000. Predicting the gas diffusion coefficient in repacked soil: water-induced linear reduction model. Soil Science Society of America Journal, 64, 1588-1594.

Penman, H.L. 1940. Gas and vapor movements in soil: the diffusion of vapors through porous solids. Journal of Agricultural Science, $\mathbf{3 0}$, 437-462.

Post, E., Forchhammer, M.D., Bret-Harte, M.S., Callaghan, T.V., Christensen, T.R., Elberling, B. et al. 2009. Ecological dynamics across the Arctic associated with recent climate change. Science, 325, $1355-1358$.

Revsbech, N.P., Nielsen, L.P. \& Ramsing, N.B. 1998. A novel microsensor for determination of apparent diffusivity in sediments. Limnology and Oceanography, 43, 986-992.

Rolston, D.E. 1986. Gases flux. In: Methods of Soil Analysis. Part 1. Physical and Mineralogical Methods. Soil Science Society of America, Book Series 5 (ed A. Klute), pp. 1103-1119. Soil Science Society of America, Madison, WI.

Rolston, D.E. \& Moldrup, P. 2002. Gas diffusivity. In: Methods of Soil Analysis. Part 4. Soil Science Society of America, Book Series 5 (eds J.H. Dane \& G.C. Topp), pp. 1113-1139. SSSA, Madison, WI.

Rolston, D.E. \& Moldrup, P. 2012. Gas transport in soil. In: Handbook of Soil Science: Properties and Processes, 2nd edn (eds P.M. Huang, Y. Li \& M.E. Sumner), pp. 1-20. CRC Press, Boca Raton, FL.

Schjønning, P., Eden, M., Moldrup, P. \& de Jonge, L.W. 2013. Two-chamber, two-gas and one-chamber, one-gas methods for measuring the soil-gas diffusion coefficient: validation and inter-calibration. Soil Science Society of America Journal, 77, 729-740.

Tarnocai, C., Canadell, J., Mazhitova, G., Schuur, E.A.G., Kuhry, P. \& Zimov, S. 2009. Soil organic carbon stocks in the northern circumpolar permafrost region. Global Biogeochemical Cycles, 23, GB2023.

Taylor, S.A. 1949. Oxygen diffusion in porous media as a measure of soil aeration. Soil Science Society of America Journal, 14, 55-61. 